\title{
World Federation of Critical Care Nurses Council Meeting, August 2005, Buenos Aires, Argentina.
}

John Albarran (UK) International representative for the British Association of Critical Care Nurses, and Executive Board Member of the European Federation of Critical Care Nursing Associations.

At the 9th World Federation of Critical Care and Intensive Care Medicine, the Argentinian Critical Care nursing association played host to the 4th WFCCN Council meeting. Associate Professor Ged Williams (Australia), out-going chair of the Federation, proclaimed that this international meeting was one of the most important critical care events ever; "a significant landmark" for the critical care nursing community.

The Council was attended by representatives from 18 countries, including South and North America (Argentina, Brazil, Canada, Chile, Colombia, Mexico and Venezuela), the European Federation (Denmark, Finland, Iceland, Slovenia, and United Kingdom), the Asia Pacific region (Australia, Hong Kong, Korea, New Zealand and the Philippines) and South Africa. Currently the WFCCN comprises 26 member organisations and further commitment has been expressed by no less than five more countries to join the Federation in the near future. The Council of Representatives also heard that South Arabian nurses were working together to develop a new group. They are planning to organise a conference and link with WFCCN once they have become more established.

\section{Key points}

The meeting was lively and generated much discussion around three main areas: the election of new Council positions, formation of a South American Federation of Critical Care Associations, and the Manila conference in 2006.

\section{Elections}

At this meeting, Ged Williams, who was the founding Chair of WFCCN, resigned from his post. Over the past five years, Ged has worked tirelessly to expand and establish the WFCCN as a reputable body of professionals. In addition, his efforts have been directed successfully to ensure that the Federation became recognised by the International Council for Nursing as the authoritative and global voice of critical care nursing. Ged's energy, passion, commitment and vision of establishing the WFCCN as a vibrant and collaborative community of critical care nurses was duly acknowledged by the incoming Chair Belle Rogado (The Philippines). She stated that Ged was one of the great nurse leaders and ambassadors of critical care nursing. Shelley Schmollgrubber, Senior Lecturer from the University of Witwatersrand, South Africa was elected unopposed to the position of Secretary. Bernice Budz (Canada) was re-elected as Treasurer for another term as was Gerardo Jasso (Mexico) who currently serves as Officer for Trade and Industry

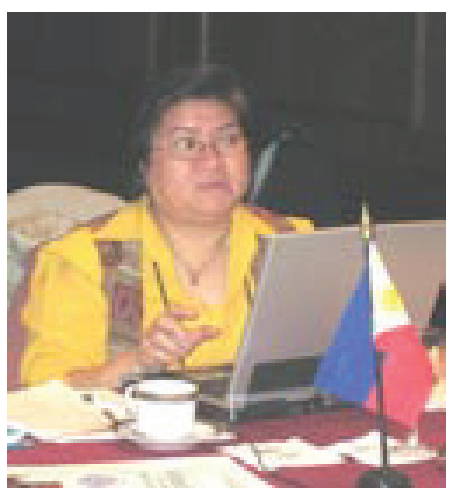

Belle Rogado Chair of WfCCN

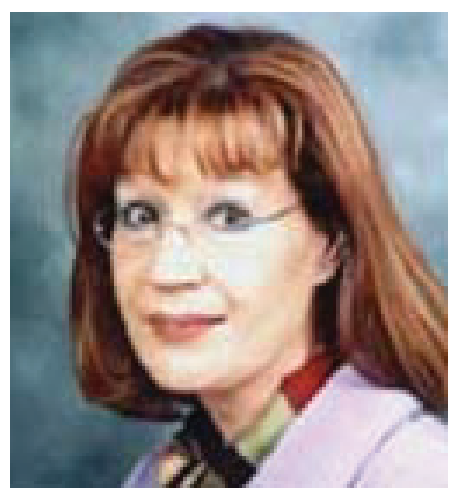

Shelley Schmollgrubber Secretary of the $\mathrm{WfCCN}$

\section{Inaugural meeting between WfCCN and South American Critical Care Leaders}

Part of the WFCCN's international strategy was to explore the opportunity to set up a new federation in South America. Representatives from Brazil, Argentina, Chile, Venezuela and Colombia attended a meeting with the WFCCN. The discussion focused on ways of establishing and supporting the new Federation. One outcome of the meeting was that Raiza Rada (Venezuela) agreed to host the first meeting to help kick-start discussions between South American critical care nursing associations in 2006. This was hailed as a major advancement particularly as this initiative has occurred over a very short period of time.

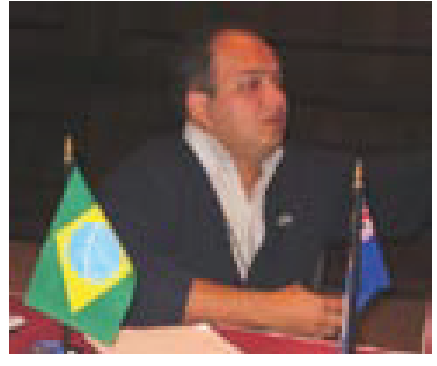

Denis Moura (Brazil)

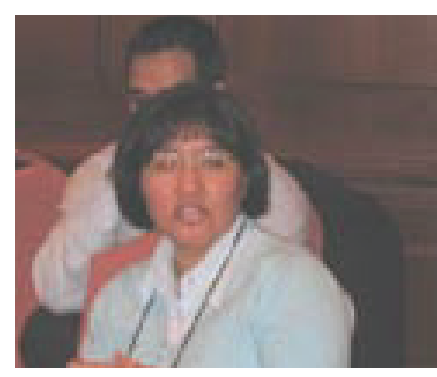

Laura Alberto (Argentina) 


\section{* World Federation of Critical Care Nurses Council Meeting, August 2005, Buenos Aires, Argentina*}

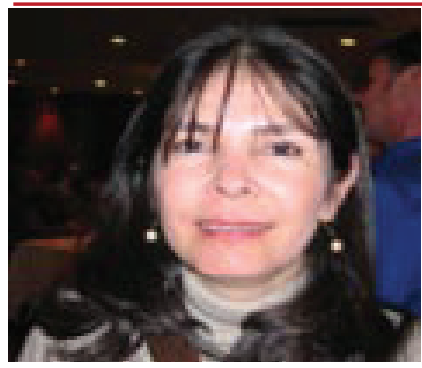

Nubia Sedano

(Colombia)

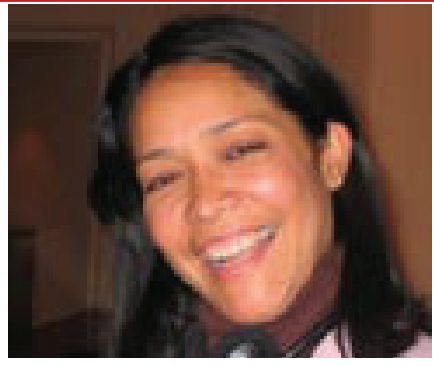

Raiza Rada (Venezuela)

\section{Manila Conference 2006}

Belle Rogado reminded the Council that the 3rd WFCCN congress in collaboration with the Critical Care Nurses Association of the Philippines, will be held in Manila from the 26th of February to $1 \mathrm{st}$ of March 2006. The conference theme is Sharing Visions- Creating missions: A convergence of Global Perspectives in Critical Care.

\section{Other major highlights}

In addition to the above, the World Federation of Critical Care Nurses also achieved the following:

* $\quad$ Agreement between WFSICCM and WFCCN of an inaugural joint meeting of Councils and a commitment to ongoing shared meetings, attendance and activities including a joint World Congress and meetings in Florence (2009)

* Official launch of two WFCCN position statements: Declaration of Buenos Aires and Declaration of Madrid

* Launch of WFCCN's first Accomplishment Report: 20012005

* The Council recognised that the web-page and journal

should become more accessible to non-English speaking critical care nurses. A commitment was made to translate into Spanish WFCCN journal abstracts and website and key organisational documents, in the coming year.

* South African colleagues extended a commitment to hosting the 4th WFCCN congress in Africa in 2007. This meeting will also provide the platform for the formation of an African federation.

* Finally, another first, this meeting was presented as a joint event by the three world critical care bodies (WFSICCM, WFCCN and WFPICS) sending a clear message that collaboration at this level is here to stay.

\section{Plans for the future}

The WFCCN will continue to engage in key strategic projects which were previously agreed, in particular the completion of a second world wide survey of critical care nursing. Other activities will revolve around reviewing the constitution, setting up a long term schedule for WFCCN meetings, revisiting marketing and publicity opportunities, devising a two year plan for 2005-2007 and developing a research agenda that reflects the aspirations of the Federation.

Reflecting on the achievements made in Argentina, Ged Willams summarised his impression by stating: "I think the Buenos Aires meeting will go down in history as one of the most significant moments when critical care nursing made its mark on the world. I think we have proven our position and credentials this week and this achievement has been through the concerted efforts of more than a hundred committed and fabulous critical care nurses all working together for a common purpose." 